\title{
AdAPTAÇÃo de ESCALAS de SILHUETAS BIDIMENSIONAIS E TRIDIMENSIONAIS PARA O DEFICIENTE VISUAL
}

\author{
AdAPTATION OF TWO AND THREE DIMENSIONAL SILHOUETTE SCALES FOR THE VISUALLY \\ IM PAIRED
}

\author{
Fabiane Frota da Rocha MORGADO ${ }^{1}$ \\ Maria Elisa Caputo FERREIRA²
}

RESU M O : o objetivo desteestudo foi descrever o processo de adaptação da Escal a deSil huetas Bidimensionais (ESB) e de criação da Escala de Silhuetas Tridimensionais (EST). Para isso uma pesquisa de cunho qualitativo realizado em três etapas: na primeira, foi solicitada a autorização do prof. Stunkard para a utilização de seu instrumento como parâmetro para a confecção das Escal as. Na segunda, foi confeccionada a ESB e na terceira, a EST. Estas Escal as foram elaboradas consi derando os critérios técnicos da Divisão de Pesquisa e Produção de Material Especializado do Instituto Benjamin Constant - RJ. Os resultados indicaram quea ESB foi confeccionada em linguagem grafo-tátil em alto relevo e é composta por nove bonecos masculinos e nove femininos, com diferentes formas corporais, texturizados com lixa de parede e linha. Os bonecos possuem $8,5 \mathrm{~cm}$ de altura. A EST foi composta por nove bonecos masculinos e nove femininos, com diferentes pesos eformas corporais. Os modelos foram confeccionados através de processo artesanal e constituídos de gesso pedra. Os bonecos do gênero masculino possuem altura de $15,5 \mathrm{~cm}$ e os do gênero feminino, $13,5 \mathrm{~cm}$. Conclui-se que as informações contidas na descrição detalhada dos processos de confecção da ESB e EST podem ser um referencial para adaptações futuras e mel horadas de outras Escal as de figuras humanas, desenvolvidas a partir deste primeiro referencial.

PALVRAS-CH AVES: Imagem Corporal. Deficiente da Visão. Linguagem Escrita.

A BSTRACT: The objective of this study was to describe the process of adaptation of the Two Dimencional Silhouette Scale (2DSS) and the development of a Three Dimensional Silhouette Scale (3DSS). To that end, a qualitative study was conducted in three stages: In the first one, the creator of the tool, Mr. Stunkard was contacted for permission to use his instrument as a parameter for the development of the scales. In the second and third ones, the 2DSS and the 3DSS were developed, respectively. Thesescales were developed considering thetechnical criteria of theBenjamin Constant Institute- RJ - of Research and Production of Specialized Materials. The results indicated that the 2DSS was developed in a graphic tactile language in high relief and is composed of nine male and nine female dolls, each with different body shapes, measured $8.5 \mathrm{~cm}$ in height and texturized with sandpaper and string. The 3DSS was composed of ninemaleand ninefemaledolls with different weights and body shapes. The models were handmade and cast in plaster. The male dolls were $15.5 \mathrm{~cm}$ in height and the female ones were $23.5 \mathrm{~cm}$ in height. We concluded that theinformation contained in the detailed description

\footnotetext{
${ }^{1}$ Mestrado em Educação Física na linha de pesquisa - Aspectos Socioculturais do Movimento Humano, na UniversidadeFederal deJuiz deFora. Fez Especialização em A spectos M etodológicos e Conceituais da Pesquisa Científica pela UniversidadeFederal de Juiz deFora (2007). Possui Graduação - Licenciatura Plena em Educação Física - pela Universidade Federal Rural do Rio de Janeiro. fabi.frm@hotmail.com

${ }^{2}$ Professora A djunto da Universidade Federal de Juiz de Fora e Orientadora nos Programas de Mestrado em Educação Física e em Psicologia. É Pós-doutora (2006) e doutora em Educação pela Universidade de São Paulo (2002). É M estre em Educação Física pela Universidade Gama Filho (1998) e M estre em Ciência da M otricidade H umana pela Universidade Castelo Branco (1996). É graduada em Educação Física pela Universidade Federal de Juiz de Fora (1993) e em Serviço Social pela Faculdade de Serviço Social do Rio de Janeiro. caputoferreira@terra.com.br
} 
of the development processes of the 2DSS and 3DSS may become a reference for future adaptations and improvements of other human figure scales.

KEYWORD S: Special Education. Body Image. Visually Impaired. Written Language.

\section{InTROdUÇÃo}

O presente estudo corresponde à parte inicial de um amplo projeto que se propõe a discutir a avaliação da Imagem Corporal do público deficiente visual. Para esta pesquisa, éimportanteesclarecer que uma das formas deinteração do cego com o mundo é através da mundividência tátil, que pode ser definida como a visão individual e particular do cego, baseada, sobretudo, na esfera tátil. Ela é a principal fonte de informações na representação mental do objeto para aqueles que não possuem o estímulo visual (SOUSA, 2004). Os modelos mais utilizados que privilegiam a mundividência tátil são o Sistema Braille 3 , a linguagem grafotátil (bidimensional) eas figuras tridimensionais. Tais modelos podem auxiliar o cego a formular imagens mentais, no entanto, não foram encontrados, no Brasil, até a presente data, modelos táteis adaptados que se propõem avaliar um componente específico da Imagem Corporal do deficiente visual (CAMPANA; TAVARES, 2009).

No que se refere às representações gráficas, passíveis de serem adaptadas ao público cego, a Escala de Silhuetas de Stunkard, Sorensen e Schlusinger (1983) tem sido largamenteutilizada com videntes nas pesquisas sobre Imagem Corporal, realizadas no Brasil (MORGADO et al., 2008). Esta Escala é composta por novefiguras humanas esquemáticas queaumentam deformagradual suas dimensões corporais e visa avaliar a satisfação corporal, um dos componentes da Imagem Corporal (SCA GLIUSI et al., 2006). Esta Imagem, segundo Schilder (1999), pode ser entendida como a representação mental do corpo, permeada por inúmeras sensações epercepções queo indivíduo vivencia eexperimenta ao longo da vida, tais como as impressões táteis, térmicas ecinestésicas, oriundas da rel ação do sujeito com o mundo. A insatisfação, por sua vez, pode ser entendida como a discrepância entre o tamanho percebido pela pessoa e o tamanho que ela gostaria deter, idealmente (FURN HAM; BADMIN; SNEADE, 2002; GARDNER, 2004).

A Imagem Corporal do cego, bem como suas imagens mentais das coisas e dos objetos são diferentes daquel as formadas pel os videntes. São formadas, especialmente, deacordo com as suas vivências táteis ena medida em queeletoca sequencialmente as coisas e os objetos para captá-los, equem enxerga possui uma visão global. Portanto, essas imagens são táteis e não visuais, e é essa experiência que importa, mesmo que seja por meio de um objeto semel hanteà "coisa". O cego podeter acesso às coisas depois de conhecêlas concretamente, lembrando-sedelas na imaginação. Portanto, há a necessidade de tocar, para saber da existência dos

\footnotetext{
${ }^{3}$ O Sistema Braille é um código utilizado internacionalmente, composto por signos representados pelas diferentes combinações de seis pontos justapostos, os quais possi bilitam ao indivíduo que não enxerga codificar e decodificar mensagens do mundo a sua volta (SOUSA, 2004).
} 
objetos, o que indica ser o tato o mais fundamental dos sentidos na formação de imagens mentais pelo sujeito que não enxerga (ORMELEZI, 2000).

Nesse contexto, torna-se relevante a adaptação e criação de materiais táteis, que possam possibilitar a comunicação do cego com o mundo e facilitar a formação deimagens mentais. Dentreos métodos de adaptação ecriação demateriais para o cego, encontram-se as figuras bidimensionais, representadas em forma de linguagem grafo-tátil, muito utilizada no processo ensino/ aprendizagem de instituições especial izadas, como o Instituto Benjamin Constant- RJ. Esta linguagem éconsiderada uma representação em al to relevo bidimensional, sem a representação deprofundidadeecomumenteutilizada para a adaptação defiguras, letras, números e símbolos em uma leitura acessível ao deficiente visual. Ela é a última etapa no processo de formação de conceitos, sendo, portanto, considerada de difícil interpretação, o que faz com que nem todos os cegos identifiquem esta linguagem.

Evidencia-se que a linguagem grafotátil é caracterizada pela texturização de desenhos gráficos. A texturização consiste em cobrir os contornos dos desenhos com inúmeros materiais, tais como diferentes tipos de linhas, com largura e espessura diversas, botões, areia, lixa de parede, papel de docinho de festa, grãos de arroz efeijão, enfim, tudo o que a imaginação possibilitar, visando à textura saliente e estimulante para o reconhecimento e a percepção tátil do deficientevisual. A pós o procedimento detexturização, os desenhos são submetidos ao thermoform, uma máquina duplicadora de materiais que emprega cal or e vácuo para produzir relevo em película de policloreto de vinila (PVC).

Além da linguagem grafotátil, uma outra forma de adaptação de materiais ao deficientevisual éa linguagem tridimensional, representada em forma de maquetes ou miniaturas. Ela pode ser entendida como uma acessível forma de "visão" do mundo pelo cego e um eficiente meio de representação gráfica, tendo em vista que o modelo em forma de maquete possui características de extensão e profundidade semelhantes e condizentes com a realidade, dado que esta é tridimensional.

É extensa a literatura que recomenda a utilização de materiais tridimensionais para serem utilizados como recursos di dáticos epedagógicos para a formação de conceitos e construção de imagens mentais pela pessoa que não enxerga. N a concepção deal guns estudiosos, tais como Batista (2005), N unes (2004), Laplane e Batista (2003) e Ormelezi (2000) a imagem tridimensional é um procedimento eficientederepresentação de esferas comuns da cultura, o quefacilita a forma de linguagem/ comunicação do deficiente visual com o mundo. Vale destacar que a representação pode ser entendida como um elemento colocado no lugar de outro (BATISTA, 2005). Os meios tridimensionais de representação são marcados por objetos reais, maquetes ou miniaturas.

Percebe-se que há maneiras diferenciadas de privilegiar a mundividência tátil. No entanto, há uma lacuna na literatura no que se refere aos materiais grafotáteis e tridimensionais, que representem diferentes dimensões e 
formas corporai ${ }^{4}$ e que possam ser aplicados como instrumento da avaliação da satisfação corporal do deficiente visual.

Este estudo pretende descrever o processo de adaptação da Escala de Silhuetas Bidimensionais e de criação da Escala de Silhuetas Tridimensionais.

\section{MÉtodo}

Esta pesquisa é de cunho qual itativo, tendo em vista sua característica de possibilitar a descrição da complexidade de determinado problema (RICHARDSON , 1999, p. 80). Para Miles eH ubeman (1994), a utilização da pesquisa qual itativa, al ém de oferecer descrições ricas sobre uma realidade específica, ajuda o pesquisador a superar concepções iniciais ea gerar ou revisar as estruturas teóricas adotadas anteriormente, oferecendo base para descrições eexplicações muito ricas de contextos específicos.

\section{Procedimentos M etodológicos}

O estudo foi real izado em três etapas: na primeira, foi solicitada via email a autorização do Doutor Albert J. Stunkard, o primeiro autor do artigo que publicou as Silhuetas em 1983, para que se pudesse adaptar a Escala original em formas delinguagem acessíveis à percepção tátil. A autorização foi concedida pelo autor, o que permitiu que o instrumento original fosse adaptado para linguagens bi e tridimensionais, passando a se chamar Escala de Silhuetas Bidimensionais (ESB) e Escala de Silhuetas Tridimensionais (EST), respectivamente.

$\mathrm{N}$ a segunda etapa, foi confeccionada a ESB. Esta fase foi realizada na Divisão de Pesquisa e Produção de Material Especializado (DPME) do Instituto Benjamin Constant (IBC), onde recebeu apoio integral dos técnicos em Braille e oferta dos materiais utilizados no procedimento de confecção. Pode-se ressaltar que esta etapa envolveu tentativas, erros eacertos, tendo sido necessário repensar alguns conceitos e decisões. Envolveu os funcionários do DPME que, com suas críticas e sugestões, nos auxiliou a chegar a um resultado considerado satisfatório pela revisora Braille do referido departamento, que é cega congênita.

Por fim, na terceira etapa, foi confeccionada a EST. Este processo teve o apoio especializado da Faculdade deA rtes eDesign da Universidade Federal de Juiz deFora ea colaboração deuma artista plástica. Estenão foi um processo linear, estanqueemecânico, mas um processo exaustivo deobservações, análises esínteses. Foi necessário, em alguns momentos, produzir modificações no curso das

\footnotetext{
${ }^{4}$ A pós um levantamento bibliográfico realizado no período correspondente a janeiro de 1993 até setembro de 2008, nas bases de dados online: Capes (Banco de Teses), Bireme, Dedalus, Sport D iscus, W eb of Science e Scielo, onde foram cruzados os descritores de busca em inglês body image com visual impairment, blind e blindness, não foram encontrados estudos que utilizaram adaptações da Escala de Silhuetas para o deficiente visual.
} 
descobertas do estudo, reorientar as posições previamente planejadas. Portanto, a paciência foi a maior aliada neste trabalho, pois em diversos momentos, foi necessário um recomeço, quando o fim parecia estar muito próximo.

\section{Critérios para a confecção das Escalas}

Tendo em vista quenão foram encontradas regulamentações específicas e legalizadas para elaboração e confecção de materiais adaptados, optou-se por elaborar a ESB e a EST, seguindo as orientações da DPME - IBC. Tais orientações constam de alguns critérios ${ }^{5}$ para a sel eção, adaptação ou elaboração de recursos adaptados. A seguir, apresentam-se os mais significativos para esta pesquisa:

- Tamanho: os materiais devem ser confeccionados ou selecionados em tamanho adequado às condições dos cegos. Materiais excessivamente pequenos não ressaltam detal hes de suas partes componentes. $O$ exagero no tamanho pode prejudicar a apreensão da totalidade.

- Significação tátil: Material deve possuir um relevo perceptível e constituir-se de diferentes texturas para mel hor destacar as partes componentes. Contrastes liso/ áspero e fino/ espesso permitem distinções adequadas.

- Aceitação: O material não deve provocar rejeição ao manuseio, como os que ferem ou irritam a pele e provoca reações desagradáveis.

- Fidelidade: o material deve ter sua representação tão exata quanto possível do modelo original.

- Resistência e segurança: A confecção deve ser com materiais que não se estraguem com facilidade, considerando o frequente manuseio pelos cegos e, ao mesmo tempo, não deve oferecer perigo para os usuários.

\section{Resultados}

Os resultados que seguem dizem respeito à descrição dos processos de confecção da ESB eEST.

\subsection{Descrição da confecção da Escala de Silhuetas Bidimensionais}

Esta etapa foi realizada em duas fases: a) Experimentos prévios eb) ESB.

Experimentos prévios

Foram confeccionadas três figuras masculinas referentes às silhuetas, 3, 6 e 9 do instrumento original, escolhidas por terem dois níveis de diferença uma

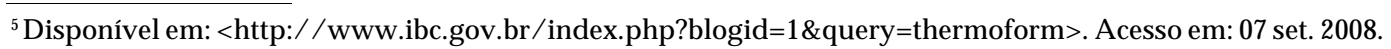


das outras. Elas foram ampliadas para $8,5 \mathrm{~cm}$, aproximadamente, epassaram pelo procedimento de "texturização", no qual foram coladas linhas da marca "A nne" em todos os contornos das Sil huetas e areia para representar o short dos bonecos. Percebeu-se que a areia era um material de difícil contenção, o que possibilitava que al guns grãos ocupassem outros espaços e confundisse o cego na hora do reconhecimento. A lém disso, foi colado al godão na barriga das figuras mais gordas. A pós a texturização das figuras, elas foram submetidas à máquina decalor chamada thermoform, quecopiou, em al to relevo, a texturização da matriz principal no PVC. Essa cópia pode ser feita inúmeras vezes a partir dessa matriz.

Esteprimeiro experimento passou pela revisora em Braille do IBC, cega congênita, que fez riquíssimas colaborações e observações quanto às figuras. Considerando-sesuas contribuições, foi realizado, então, um segundo experimento, nos mesmos três bonecos, porém, a textura da roupa de banho foi trocada por uma lixa de paredeno lugar da areia. O algodão colocado anteriormentena barriga dos bonecos foi retirad o devido a um relevo excessivo no PVC queconfundiu a revisora. Tal experimento foi novamenteaval iado pela revisora efoi considerado adequado para o reconhecimento. Resolveu-se, assim, confeccionar as 18 figuras: nove representativas dos modelos femininos e nove representativas dos modelos masculinos, com base neste segundo procedimento.

\section{Escala de Silhuetas Bidimensionais}

Para esta Escala, foi proposto pelos técnicos do DPME que todas as nove figuras de silhuetas representantes do gênero feminino ou masculino coubessem em um único plano para facilitar o processo de comparação. Dessa forma, as figuras mantiveram o mesmo tamanho do experimento prévio, aproximadamente $8,5 \mathrm{~cm}$, considerando uma proporção máxima deampliação, de maneira que todas coubessem em uma única folha de papel do tamanho $47 \times 36$ $\mathrm{cm}$, um limite apropriado para a máquina dethermoform do IBC. Essetipo defolha é muito utilizado para texturização de mapas e esquemas.

No procedimento de texturização, foram utilizadas linhas de crochêe lixas de parede para cobrir os contornos dos desenhos. As linhas foram coladas com cola escolar da marca "Tenaz" e as lixas foram col adas com cola em bastão da marca "Pritt Henkel". A linha da marca "A nne" foi colada nos contornos externos das Silhuetas, já os contornos internos, como linha do joelho, cabel os e traços da face, foram feitos com a colagem de uma linha um pouco mais fina, cuja marca é "Cléa". Uma lixa deparedefoi cortada conforme o modelo do maiô para as bonecas e da bermuda para os bonecos e, posteriormente, colada no desenho. A pós a texturização das figuras, elas foram submetidas ao thermoform, quecopiou em al to relevo a texturização da matriz principal no PVC. Dessa forma, estava concluída a ESB (Figura 1), que poderia ser copiada inúmeras vezes. 
Figura 1 - Desenho da Escala de Silhuetas Bidimensionais

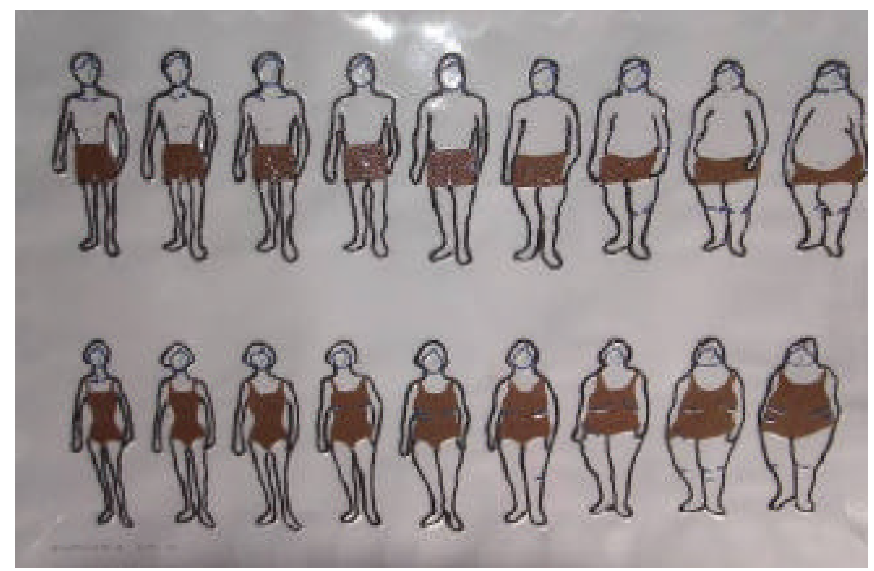

Fonte: Material registrado e produzido pela pesquisadora, em junho de 2008.

\subsection{Descrição da confecção da Escala de Silhuetas Tridimensionais}

As etapas deelaboração econfecção das silhuetas tridimensionais foram realizadas em seis momentos complementares: a) Experimentos prévios; b) Confecção denovemodelos masculinos em argila; c) Construção dos modelos mais gordos de cada sexo em argila; d) Confecção dos 18 modelos em gesso e confecção das 18 fôrmas em silicone; e) Tentativas de modelos em silicone e f) Escala de Silhuetas Tridimensionais.

\section{Experimentos prévios}

Inicialmente, uma modeladora artista plástica construiu em argila três modelos provisórios do gênero feminino, representantes das figuras 3, 6 e 9 da Escala de Stunkard, escolhidas por terem dois níveis de diferença uma das outras. Foi constatada uma diferença significativa na altura dos bonecos, o que poderia tirar a atenção dos cegos quanto às dimensões corporais. Foi notado ainda quehavia assimetria entre os lados direito e esquerdo dos bonecos, sendo necessárias al gumas adaptações.

\section{Confecção de nove model os masculinos em argila}

Em um segundo momento, foram confeccionados nove modelos masculinos em argila. N esta fase, houvea preocupação de ressal tar al guns detal hes na maquetepara queficassem mais perceptíveis ao tato, por exemplo, foi feita textura, ou seja, riscos diagonais na bermuda dos bonecos e esses foram ampliados para $12 \mathrm{~cm}$, aproximadamente. A lém disso, houveumatentativa derealizar as adaptações sugeridas a partir dos experimentos prévios (padronização da altura emanutenção da simetria entre os lados direito e esquerdo). No entanto, percebeu-se que, ao final dessa etapa, os bonecos continuavam com uma diferença de al tura significativa entre si. 
A pesar do conhecimento prévio deque os modelos em argila poderiam diminuir em até 30\% de seu tamanho com a argila molhada, depois de seco, essa redução não foi linear. Al guns bonecos diminuíram 30\%, como os mais magros, já outros quase não diminuíram, principalmente os mais gordos. Além disso, por ser um processo de confecção sequencial e artesanal, cada figura demonstrava características físi cas diferentes, por exemplo, cada uma tinha um rosto. Sabia-se que, no instrumento do Stunkard, um mesmo indivíduo engorda ou emagrece, já nos modelos masculinos confeccionados, nesta segunda fase, parecia que eram vários indivíduos gordos e magros.

Para sanar esses contratempos, depois que as figuras masculinas em argila foram cuidadosamente analisadas, tentou-se uma outra possibilidade de adaptação, que pudesseanular ou diminuir as questões queainda inquietava: al tura e características das feições diferenciadas. A nova proposta era trabal har no gesso enão mais na argila. Essetipo de material não muda significativamentedetamanho depois de seco. A partir de então, teve-se um novo recomeço.

\section{Construção dos model os mais gordos de cada sexo em argila}

Os bonecos relacionados à Figura 9 do instrumento original, ou seja, o mais gordo de cada sexo, foram construídos em argila na dimensão de $13.5 \mathrm{~cm}$ para a mulher e $15,5 \mathrm{~cm}$ para o homem (figura 2). A al tura dos bonecos teve como referência o tamanho da mão de uma mulher e de um homem adultos, para as maquetes femininas e masculinas, respectivamente. Isso foi feito com base no pressuposto de que as miniaturas deveriam caber na mão de um adulto, sem ultrapassar seus limites e, ao mesmo tempo, com um tamanho ideal para o reconhecimento pelo cego. Tendo em vista que a mão do homem é relativamente maior do que a da mulher, houve o cuidado de que a ampliação do boneco masculino fosse $2 \mathrm{~cm}$ maior do que o feminino.

Figura 2 - Boneco de argila criado a partir da figura 9 da Escal a de Stunkard

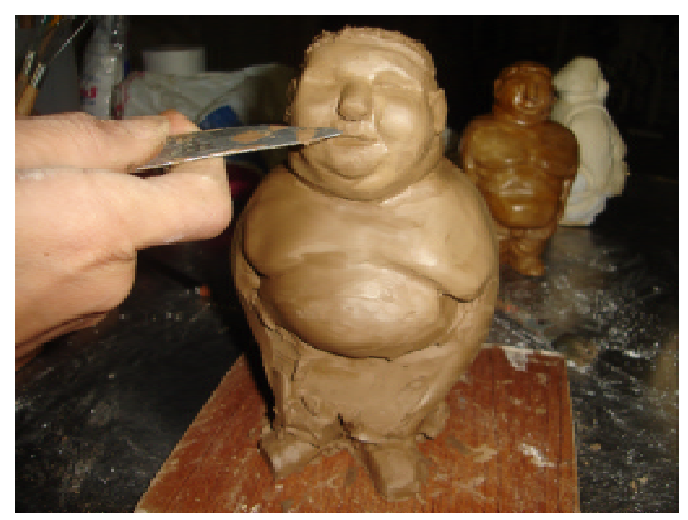

Fonte: foto tirada pela pesquisadora em novembro de 2008. 
Nesta fase, houve um cuidado especial em detalhar os contornos corporais, enfatizando as gorduras abdominais, pélvicas, dorsais e dos membros. Alguns detal hes como olhos, nariz e boca foram acrescentados, ponto que difere do instrumento original quenão apresentava contornos faciais. Esses detal hes foram acrescentados para facilitar o reconhecimento de Silhuetas humanas pelos cegos. A lém disso, foi colocada textura nas roupas (maiô e bermuda) dos bonecos com o intuito de facilitar a percepção tátil.

\section{Confecção dos 18 model os em gesso e das 18 fôrmas em silicone}

A pós a el aboração dos model os em argila relacionados às Figuras 9 de cada sexo, foram feitas as fôrmas de silicone para cada um desses exemplares. Um experimento prévio foi feito com a fôrma de alginato, mas esta tem pouca durabilidade, possibilitando somente duas ou três cópias. Então, decidiu-sefazer a fôrma desilicone, que possi bilita a cópia de um il imitado número deexemplares.

Em princípio, foi construída uma fôrma de gesso, com duas metades. Os bonecos, após impermeabilizados com gomalaca e lubrificados com vasel ina sólida foram cobertos com uma camada de argila. Esse composto foi apoiado em uma pequena camada de gesso feita dentro de um pote de sorvete, que já estava untado com cera sólida. Em seguida, o gesso foi completado até atingir a metade da "embalagem em argila", como consta na figura 3:

Figura 3 - Boneco de argila em processo de confecção da fôrma de gesso

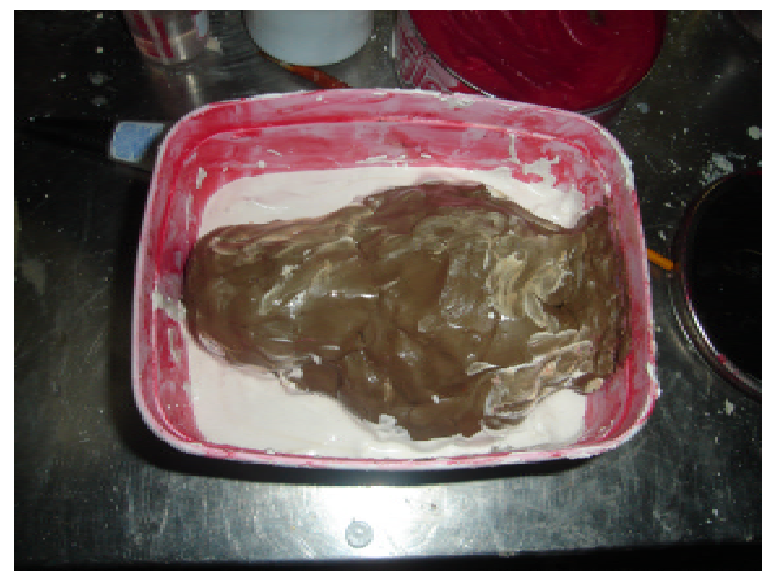

Fonte: foto tirada pela pesquisadora em novembro de 2008.

A pós a secagem dessa camada degesso, o mesmo foi impermeabilizado com gomalaca e lubrificado com cera sólida. Em seguida, foi feita uma terceira camada de gesso até que atingisse a superfície do recipiente. A pós esse processo, o composto de gesso foi retirado do pote e cuidadosamente aberto, formando duas 
metades. O boneco foi retirado do interior da fôrma de gesso. Esta foi impermeabilizada com gomalaca, como exemplificado na Figura 4.

Figura 4 - Fôrma de gesso aberta em duas metades

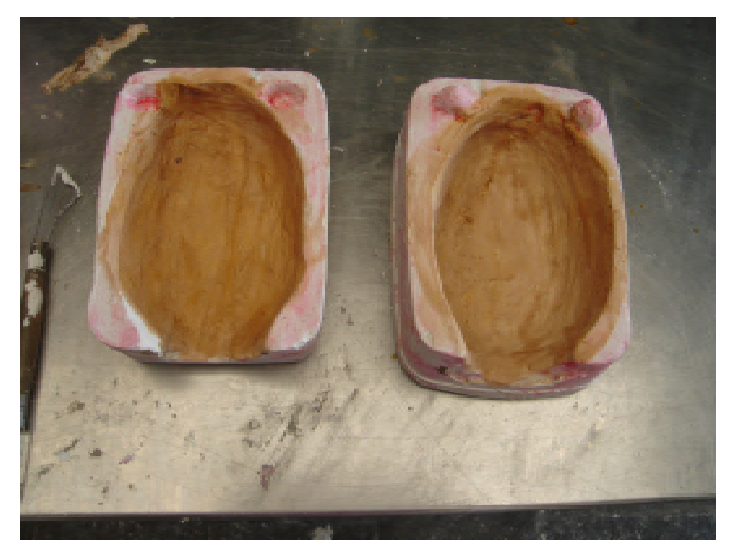

Fonte: foto tirada pela pesquisadora em novembro de 2008.

A argila foi retirada do entorno do boneco. Nos pés do boneco, foi colado um fino pedaço de madeira com a cola "super bonder". Ele então foi pendurado de cabeça para baixo dentro do recipiente de gesso. Esse recipiente foi amarrado com borracha e as laterais foram vedadas com argila. O local, que antes era ocupado por argila, agora foi preenchido com silicone líquido misturado com catalisador (Figura 5).

Figura 5 - Boneco de argila em processo de confecção da fôrma de silicone

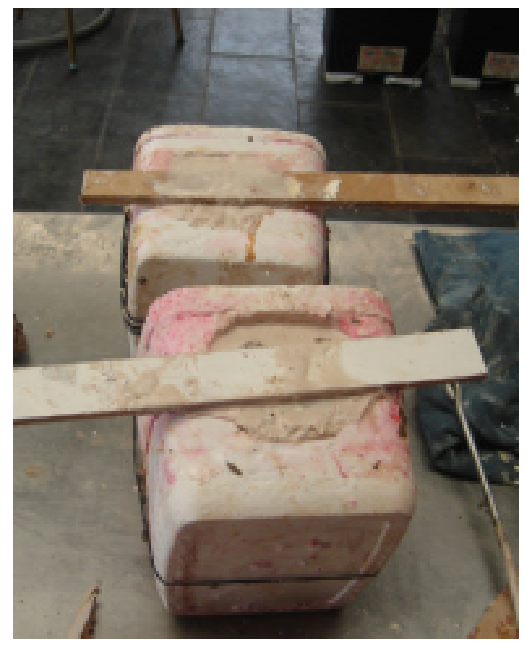

Fonte: foto tirada pela pesquisadora em novembro de 2008. 
O siliconesecou em 24 h, e, após esse período, a fôrma degesso foi aberta eo siliconequeenvolvia o modelo em argila, retirado. Foi feito um cortelateral com um estilete na borracha de silicone para resgatar o boneco. Em seguida, a fôrma estava pronta para reproduzir bonecos de gesso, como demonstra a Figura 6.

Figura 6 - Fôrmas de gesso e fôrmas de silicone

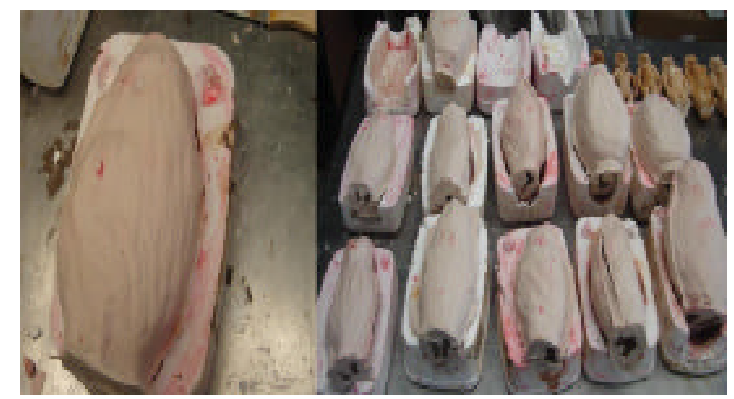

Fonte: foto tirada pela pesquisadora em novembro de 2008.

Para reproduzir bonecos em gesso, bastava fechar a fôrma de silicone, colocá-la dentro do recipiente de gesso, vedar o recipiente, preparar o gesso e derramar, cuidadosamente, dentro da fôrma de silicone. Assim, um boneco de gesso era confeccionado a partir do modelo 9 de argila. Esse boneco foi, então, lapidado até emagrecer para atingir uma medida determinada de acordo com o instrumento original e se transformar no modelo 8. A partir daí, uma nova fôrma foi confeccionada. Novamente, foi reproduzido um novo boneco, a partir do modelo 8 lapidado em gesso. Esteexemplar emagrecia mais uma medida, transformandose no modelo 7 em gesso; uma nova fôrma foi feita e assim sucessivamente, até que os noves exemplares masculinos efemininos fossem construídos. Dessa forma, todas as miniaturas mantiveram, aproximadamente, a mesma al tura e as mesmas características faciais, já que foram feitas em gesso e partiram do mesmo modelo em argila.

Tentativas de model os em silicone

A pós a confecção das fôrmas de gesso e silicone nas etapas anteriores, houve inúmeras tentativas de reproduzir um boneco de siliconea partir da fôrma desse mesmo material. N o entanto, não foi encontrado um impermeabilizador que proporcionasse bons resultados. Tentou-se utilizar esmalte sintético com silicone industrial, mas o boneco de silicone apresentava partes que grudavam na fôrma, destruindo-a. A mesma tentativa foi feita com gomalaca e silicone industrial, mas os resultados também foram negativos. Por fim, foi utilizada tinta duco automotiva, no entanto, essa foi mais uma tentativa frustada, pois a tinta duco descascou completamente da fôrma, então, foi necessário repensar os próximos passos. 


\section{Escala de Silhuetas Tridimensionais}

Diante das inúmeras tentativas frustadas para confeccionar os modelos em silicone, foi necessário pensar na possibilidade de utilizar o boneco de gesso para construir a ESB. A pós sua confecção, os bonecos foram submetidos ao julgamento da mesma revisora em Braille do IBC, que já havia analisado o modelo bidimensional. Ela mostrou-se preocupada em quebrar algum dos exemplares. Diante dessa constatação, houve o cuidado de utilizar uma marca de gesso que proporcionasse maior resistência e durabilidade. Foi utilizado o Gesso Pedra V igodent, que é um tipo de gesso resistente e de endurecimento rápido, indicado para confecção de trabal hos dentários e sua expansão é de 0,30\% (alta).

Por fim, os 18 bonecos femininos emasculinos, com diferentes tamanhos corporais, foram construídos com uma forma tátil de representação tridimensional da Escala de Stunkard para os cegos, como consta na Figura 7. Os modelos foram pintados visando uma textura mais saliente ao tato.

Figura 7 - Escala de Silhuetas Tridimensionais (EST)

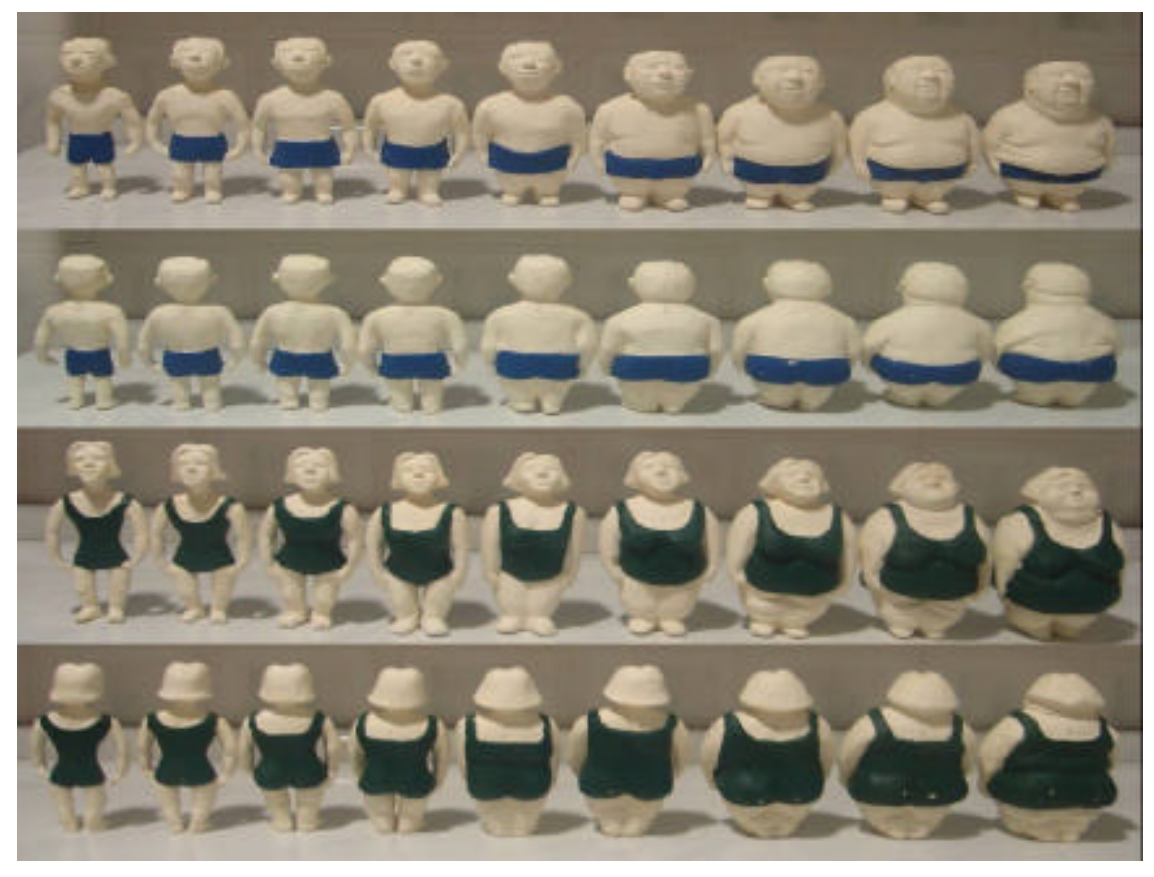

Fonte: Elaborada pela autora em dezembro de 2008.

\section{Discussões}

Alguns estudiosos, como Laplanee Batista (2003), além deN unes (2004), investigaram o desenvolvimento de conceitos pelo cego e afirmaram que os materiais adaptados são grandes facilitadores para a formação de tais conceitos. 
Eles destacaram ser urgente que os profissionais que lidam com este público se empenhem para adaptar o maior número possível de materiais que possam representar determinado fenômeno ou objeto. Neste estudo, a proposta de adaptação é referente a um instrumento comumente usado para videntes na avaliação da sua satisfação corporal, chamado Escala de Silhuetas de Stunkard, Sorensen e Schlusinger (1983).

Cumpre esclarecer que, embora os meios e formas de adaptação de materiais para o cego sejam antigos, como afirma Souza (2004), poucos estudos privilegiam a descrição detal hada da confecção desses materiais. Na descrição do presente estudo, o processo artesanal, possibilitado pela assistência profissional dos técnicos em Braille do Instituto Benjamin Constant e dos professores da Faculdade de Arte e Design da Universidade Federal de Juiz de Fora, pôde ser considerado uma fonte relevante de subsídios para adaptação da ESB e criação da EST para os deficientes visuais. N esse contexto, cada vez mais, torna-se necessário um diálogo entreos profissionais das diferentes áreas do saber na busca do material mais adequado e do processo de elaboração, adaptação e criação de objetos táteis mais eficientes para o sujeito que não enxerga.

Para este estudo, a formação de uma equipe multidisciplinar formada por professores deEducação Física, artistas plásticos, professores deA rtes eDesign, técnicos, especialistas e revisores em Braille, proporcionou uma rica troca de informações, quetornou possível a adaptação e construção das Escal as. A adaptação da ESB e a criação da EST visaram atender aos aspectos de percepção tátil eforam confeccionadas respeitando a maneira específica de "visão" do indivíduo cego. Dessa maneira, fez-seuso detexturas, relevos, pesos diferenciados eformas diversas que privilegiassem, sobretudo, a mundividência tátil.

No entanto, concorda-secom Laplanee Batista (2003), quando afirmam que muito resta a fazer na adaptação e criação de recursos para o cego e que é necessário balizar a elaboração desses recursos, tendo em vista as especificidades desse público. Portanto, os materiais devem ser adaptados de acordo com as possibilidades de interpretação e reconhecimento do cego. Frente a estas constatações, tanto a ESB quanto a EST foram submetidas à avaliação de uma revisora em Braille do Instituto Benjamin Constant, que é cega congênita.

Tal avaliação foi fundamental, na medida em que ofereceu aos pesquisadores, referências sobre representação das Escalas deSil huetas para uma pessoa que nunca enxergou. Desse modo, foi possível realizar algumas novas adaptações que tornassem as Escalas mais representativas ao cego. Vale lembrar que as sensações que trazem informações sobre o mundo e os objetos são diferenciadas nos indivíduos cegos e videntes. N os sujeitos que não enxergam, as sensações táteis possuem especial relevância para a percepção das coisas e objetos (DOLTO; NASIO, 2008; DAMÁSIO, 2000).

O filósofo Merleau-Ponty (2007, p. 131) demonstra que o estímulo físico associado às qualidades do sensível, principalmentedo tátil, permitem o espetáculo 
do visível e ressalta que a relação do sujeito com o mundo, durante toda a sua existência, é fundamental para a visão: “É preciso que nos habituemos a pensar que todo visível é moldado no sensível, todo ser táctil está voltado de alguma maneira à visibilidade".

O tato constitui, portanto, um sistema sensorial que possui determinadas características imprescindíveis ao indivíduo que nunca enxergou, pois permite a captação de diferentes propriedades físicas dos objetos, tais como temperatura, textura, forma erel ações espaciais. A ESB ea EST são propostas táteis que podem possi bilitar al guma forma de comunicação do cego com o mundo.

\section{Conclusões}

A proposta deste estudo consistiu em descrever o passo a passo da adaptação das Escalas bi etridimensionais, o que poderá servir de incentivo para profissionais da área da saúde, quelidam com o público deficiente visual, a adaptar novos materiais que pretendem avaliar um componente da Imagem Corporal do deficiente visual. N esta pesquisa, valorizou-se sobremaneira a mundividência tátil, visto quea adaptação da ESB ea criação da EST podem beneficiar a forma tátil que o cego vêo mundo e se comunica com ele.

É importante destacar que os materiais, cuja adaptação inicial foi descrita aqui, não pretendem oferecer respostas definitivas no que diz respeito a sua adequação aos sujeitos deficientes visuais. O objetivo é fomentar ainda mais a discussão acerca da adaptação ou da criação de novos materiais que visem avaliar diferentes componentes da I magem Corporal do deficientevisual . A s informações conti das na descrição detal hada dos processos de confecção da ESB e EST podem ser um referencial para adaptações futuras emelhoradas deoutras Escal as defiguras humanas, desenvolvidas a partir deste primeiro referencial.

As tentativas frustradas, os erros e acertos deste estudo podem servir como ponto de partida para outras investigações sobre adaptações de Silhuetas, evitando desperdício detempo epoupando energias que poderiam ser canalizadas para o aprimoramento do que já foi feito até o presente momento. Sugere-se a realização de estudos futuros queexplorem a ESB eEST, verificando seestas Escalas são representativas para um grupo aumentado de deficientes visuais e se podem ser aplicadas como uma forma de avaliar a insatisfação corporal deste grupo.

\section{ReferênCIAS}

BATISTA, C. G. Formação de conceitos em crianças cegas: questões teóricas e implicações educacionais. P sicologia: Teoria e Pesquisa, Brasília, v. 21, n. 1, p. 7-15, 2005. 
CAMPANA, A. N. N. B. C.; TAVARES, M. C. G. C. A valiação da Imagem Corporal: instrumentos e diretrizes para a pesquisa. São Paulo: Phorte, 2009.

DOLTO, F.; NASIO, J. D. A criança do espel ho. Trad. André Telles. Rio de Janeiro: Jorge Zahar, 2008.

DAMÁSIO, A. R. 0 mistério da consciência: do corpo edas emoções ao conhecimento em si. Trad. Laura Teixeira Motta. 7. reimp. São Paulo: Companhia das Letras, 2000.

FURNHAM, A.; BADMIN, N.; SNEADE, I. Body Image Dissatisfaction: Gender Differences in Eating Attitudes, Self-Esteem, and Reasons for Exercise. The J ournal of Psychology, London, v. 136, n. 6, p. 581-596, 2002.

GARDNER, R. M. Body Image A ssessment of Children. In: CASH, T., PRUZINSKY, T. B ody Image: a handbook of theory, research $\&$ clinical practice. N ova lorque: Guilford Press, 2004.

LAPLANE, A . L. F.; BATISTA, C. G. Um estudo das concepções de professores de ensino fundamental e médio sobre a aquisição de conceitos, aprendizagem e Deficiência Visual [Resumo]. In: CONGRESSO BRASILEIRO DE EDUCAÇÃO ESPECIAL, 1, IX CICLO DE ESTUDOSSOBRE DEFICIÊN CIA MENTAL 2003. São Paulo. A nais..., São Paulo: UFSCar, 2003, p. 14-15.

MERLEAU-PONTY, M. 0 visível e o invisível. Trad. JoséA rtur Gianotti eA rmando Mora d'Oliveira. 4. ed. São Paulo: Perspectiva, 2007.

MILES, M.; HUBERMAN , M. Q ualitative data analysis. London: Sage Publications, 1994.

MORGADO, F. F. R. et al. Analysis of the Body Image Assessment Protocols published in Brazil. Fiep Bulletin, Foz do Iguaçú, v. 78, p. 12-15, 2008, Special Edition.

NUNES, S. S. D esenvolvimento de conceitos em cegos congên itos: caminhos deaquisição do conhecimento. 2004. 287 f. Dissertação (Mestrado em Psicologia) - Instituto de Psicologia, Universidade de São Paulo, São Paulo, 2004.

ORMELEZI, E. M. O s caminhos da aquisição do conhecimento ea cegueira: do universo do corpo ao universo simbólico. 2000. 273f. Dissertação (M estrado em Psicologiae Educação) - Faculdade de Educação, Universidade de São Paulo, São Paulo, 2000.

RICHARDSON, R. J. Pesquisa social: métodos e técnicas. São Paulo: Atlas, 1999.

SCAGLIUSI, F. B. et al. Concurrent and discriminant validity of the Stunkard's figure rating scale adapted into Portuguese. A ppetite, v. 47, p. 77-82, 2006.

SOUSA, J. B. A spectos comunicativos da percepção tátil: a escrita em relevo como mecanismo semiótico da cultura. 2004. 176f. Tese (Doutorado em Comunicação e Semiótica) - Faculdade de Comunicação, Pontifícia Universidade Católica de São Paulo, São Paulo, 2004. 
SCHILDER, P. A imagem do corpo: as energias construtivas da psique. 3. ed. São Paulo: Martins Fontes, 1999.

STUNKARD, A. J.; SOREN SEN, T.; SCHLUSINGER, F. Use of theDanish A doption Register for the study of obesity and thinness. In: KETY, S.S.; ROWLAND, L.P.; SIDMAN, R.L.; MATTHYSSE, S.W. (Eds). The genetics of neurological and psychiatric disorders. New York: Raven, 1983, p. 115-20. 